\title{
LIMITS AND DIFFERENCE: PRECONDITIONS FOR COMPARATIVE ADVANTAGE
}

\author{
David Tucker, Concordia University, Portland, Oregon, U.S.A.
}

dx.doi.org/10.18374/JIMS-20-1.6

\begin{abstract}
The economic law of comparative advantage has been a staple of economics textbooks for 200 years. Less well understood is the anthropology of human beings that form the preconditions for comparative advantage. Each human being is created with limitations of time, and each human being is different from other human beings. The exploration of the meaning of these two ideas, especially through a theological lens, generates the law of comparative advantage, and the possibility of prosperity through relationships of mutually beneficial exchange.
\end{abstract}

Keywords: limits, difference, comparative advantage. 